\title{
The United Kingdom's first NHS EndoBarrier service for long-standing poorly controlled type 2 diabetes and obesity: outcomes one year after EndoBarrier removal
}

\author{
ROBERT EJ RYDER, ${ }^{1}$ MAHI YADAGIRII, WYN BURBRIDGE, ${ }^{1}$ SUSAN P IRWIN, ${ }^{1}$ HARDEEP GANDHI, ${ }^{1}$ \\ TAHIRA BASHIR, ${ }^{1}$ RACHAEL A ALLDEN, ${ }^{1}$ MELANIE WYRES, ${ }^{1}$ MELISSA CULL, ${ }^{1}$ JOHN P BLEASDALE, ${ }^{1}$ \\ EDWARD N FOGDEN, ${ }^{1}$ MARK R ANDERSON, ${ }^{1}$ PIYA SEN GUPTA ${ }^{1,2}$
}

\begin{abstract}
Aims: EndoBarrier is a $60 \mathrm{~cm}$ duodenal-jejunal bypass liner endoscopically implanted for up to one year. It mimics the bypass part of Roux-en-Y bariatric surgery and reduces weight and $\mathrm{HbA}_{1 \mathrm{c}}$ while it is in situ. We aimed to assess the extent to which these improvements are sustained in people with diabetes in the year following removal.

Methods: Between October 2014 and November 2017 we implanted 62 EndoBarriers in an NHS service with all removed by November 2018. Outcomes were monitored in a registry. Results: By November 2019, 46/62 (72\%) (mean \pm SD age $51.5 \pm 7.7$ years, $52 \%$ male, $54.3 \%$ white ethnicity, median (IQR) diabetes duration 14.5 (8-20) years, 67.4\% insulintreated and mean \pm SD body mass index (BMI) 41.6 \pm 7.1 $\left.\mathrm{kg} / \mathrm{m}^{2}\right)$ had attended and $16 / 62(28 \%)$ did not attend their one-year post-EndoBarrier follow-up appointment. In those who attended, during EndoBarrier implantation mean \pm SD $\mathrm{HbA}_{1 \mathrm{c}}$ fell by $21.1 \pm 19.6 \mathrm{mmol} / \mathrm{mol}$ from $77.1 \pm 20.0$ to $56.0 \pm 11.2 \mathrm{mmol} / \mathrm{mol}(p<0.001)$ (by $1.9 \pm 1.8 \%$ from $9.2 \pm 1.8 \%$ to $7.3 \pm 1.0 \%(p<0.001))$, weight fell by $17.2 \pm 8.8 \mathrm{~kg}$ from $121.9 \pm 29.4 \mathrm{~kg}$ to $104.7 \pm 30.1 \mathrm{~kg}(p<0.001)$, BMI fell from $41.6 \pm 7.5$ to $35.5 \pm 7.5 \mathrm{~kg} / \mathrm{m}^{2}$ ( $\left.<<0.001\right)$, systolic blood pressure from $139.0 \pm 14.0$ to $126.0 \pm 14.6 \mathrm{mmHg}(p<0.001)$ and serum alanine aminotransferase from $30.0 \pm 16.9$ to $18.8 \pm 11.0 \mathrm{U} / \mathrm{L}$ $(p<0.001)$. Median (IQR) total daily insulin dose reduced from $104(54-162)$ to $30(0-62)$ units $(n=31, p<0.001) ; 10 / 31(32 \%)$ insulin-treated people with diabetes were able to discontinue insulin. One year post-EndoBarrier, 18/46 (39\%) demonstrated fully sustained improvement, 18/46 (39\%)
\end{abstract}

Sandwell \& West Birmingham NHS Trust, City Hospital, Birmingham, UK Guy's and St Thomas' Hospitals, London, UK

Address for correspondence: Dr Bob Ryder

Sandwell \& West Birmingham NHS Trust, City Hospital, Dudley Road,

Birmingham B18 7QH, UK

E-mail: bob.ryder@nhs.net

Tel: +44 (0)1215075723

https://doi.org/10.15277/bjd.2021.295 partially sustained improvement and 10/46 (22\%) reverted to baseline. Of those deteriorating, $9 / 10(90 \%)$ had depression and/or bereavement; they also had less fall in weight and $\mathrm{HbA}_{1 \mathrm{c}}$ during EndoBarrier treatment. In the 16/62 (28\%) who did not attend follow-up, reasons for non-attendance were too far to travel $(25 \%)$, need to take time off work (6.3\%), severe depression (6.3\%) and death (6.3\%). In 56.3\% of cases no reason was given.

Conclusion: Our data demonstrate that EndoBarrier is highly effective in people with long-standing poorly controlled type 2 diabetes and obesity, with maintenance of significant improvement one year after removal in $78 \%$ of cases for whom data were available. As an endoscopic procedure it is relatively simple and non-invasive and it deserves further investigation.

Br J Diabetes 2021;21:76-83

Key words: EndoBarrier, duodenal-jejunal bypass liner, DJBL, obesity, type 2 diabetes, diabesity, bariatric surgery

\section{Introduction}

Background and rationale

EndoBarrier $^{\circledR}$ (GI Dynamics, Boston, USA), also known as the duodenal-jejunal bypass liner, is a $60 \mathrm{~cm}$ long impermeable fluoropolymer sleeve which is implanted by endoscopy into the first part of the small intestine where it remains for about one year (Figure 1). It is held in place by a nitinol anchor, such that food passes through it without coming into contact with the small intestine, thereby mimicking the bypass part of Roux-en-Y bariatric surgery. ${ }^{1-3}$ The endoscopic insertion and removal of EndoBarrier are day case procedures, performed in less than an hour under general anaesthesia. This form of reversible bariatric procedure has been shown to reduce weight and improve glycaemic control in people with diabetes and obesity. ${ }^{2-8}$

As previously described in detail elsewhere, ${ }^{8}$ we established in 2014 a National Health Service (NHS) service providing EndoBarrier treatment to people with long-standing poorly controlled type 2 diabetes and obesity which continued to be a problem despite all attempts to improve the situation with diet and lifestyle mea- 
Figure 1. (a) The EndoBarrier device and (b) a diagram of the device in siut

(a)
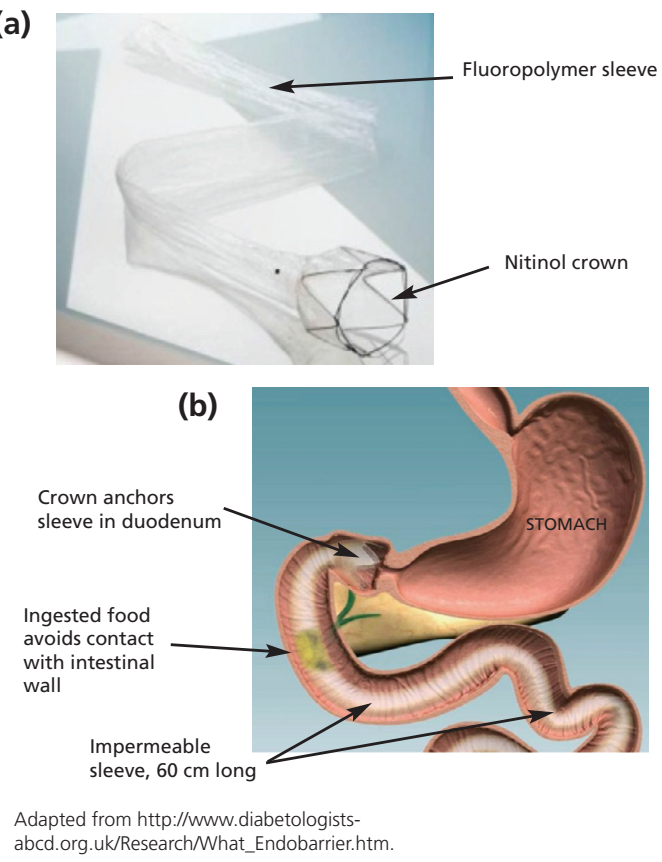

sures as well as available diabetes medications. We treated 62 people with diabetes with EndoBarrier in this service. ${ }^{8}$ By November 2018 all 62 had had the EndoBarrier removed and we were able to demonstrate ${ }^{8}$ considerable improvements in haemoglobin A1c $\left(\mathrm{HbA}_{1 \mathrm{c}}\right)$, weight, systolic blood pressure, cholesterol, alanine aminotransferase as a marker of non-alcoholic fatty liver disease, ${ }^{9}$ and in the need for insulin. There were also significant falls in the risk of coronary heart disease and stroke as indicated by the UKPDS Risk Engine v2..$^{8,10}$ We gave details of the 10 out of 62 people with diabetes requiring early removal due to side effects, all of whom made a full recovery following device removal with most deriving considerable benefit despite the early removal. ${ }^{8}$

Despite the dramatic impact of this endoscopic treatment on so many health parameters, there remains uncertainty regarding the extent to which such EndoBarrier-induced improvements are maintained following its removal. ${ }^{2}$ We therefore aimed to follow our 62 people with diabetes during the year after EndoBarrier removal to assess the extent to which the benefits were sustained.

\section{Methods}

\section{Study design and setting}

We have described previously a comprehensive two-year pathway for the management of these people with diabetes who were seen at the Diabetes Centre at City Hospital in Birmingham, UK, in an NHS clinic specifically set up for the purpose. ${ }^{8}$ During the year following EndoBarrier removal there were telephone consultations between the patient and Diabetes Specialist Nurse (DSN) one week and one month after removal of EndoBarrier. Thereafter there were three-monthly clinic consultations with the DSN and diabetes physician, with dietician consultation according to need. Interim consultations with DSN by telephone or in clinic were also sometimes arranged according to need. We have also described the requirements of the insertion and removal procedures. ${ }^{8}$ The first EndoBarrier implantation in the NHS service was in October 2014, with the last one in November 2017 and the last EndoBarrier was removed in November 2018. Thus, by November 2019, all had reached one year after EndoBarrier removal and the findings at that time are the subject of this report.

\section{Participants}

As previously described in detail, ${ }^{8}$ all the patients had type 2 diabetes, were aged between 28 and 70 years, body mass index $(\mathrm{BMI})>30 \mathrm{~kg} / \mathrm{m}^{2}$ and had tried diet, lifestyle and medications including glucagon-like peptide-1 (GLP-1) receptor agonists and, once available, sodium-glucose co-transporter-2 (SGLT2) inhibitors if within licence. Thus, the only options left for them were to start insulin, increase insulin further if already on insulin, or to have bariatric/metabolic surgery or alternative procedures not yet available on the NHS. ${ }^{8} \mathrm{HbA}_{1 \mathrm{c}}>58 \mathrm{mmol} / \mathrm{mol}(7.5 \%)$ was generally required. Lower $\mathrm{HbA}_{1 c}$ was acceptable only if patients were already established on insulin and it was considered that their insulin treatment to maintain the lower $\mathrm{HbA}_{1 \mathrm{c}}$ was contributing significantly to the obesity. ${ }^{8}$

\section{Variables}

As previously detailed, ${ }^{8}$ we recorded baseline age, sex, ethnicity, smoking history, diabetes duration and medications. At baseline and at three-month intervals during the period following EndoBarrier insertion and during the year after removal, parameters measured included $\mathrm{HbA}_{1}$, weight, $\mathrm{BMI}$, systolic blood pressure, alanine aminotransferase and diabetes medications including insulin dose if applicable. Side effects were recorded, in particular gastrointestinal, and any serious adverse events leading to early removal of EndoBarrier as has previously been reported. ${ }^{8}$ We also collected and have reported patient satisfaction as assessed with the NHS Friends and Family Test. ${ }^{8,11}$ Weight and height were measured on standard outpatient equipment. Biochemistry parameters were measured in the pathology department at City Hospital.

\section{Sources of bias}

Because we were auditing routine clinical practice, we could not interfere with standard care which might have impacted on the results - for example, medications for other conditions such as steroids for inflammatory conditions or medications for mental health. There was no control group for comparison and there was no blinding.

\section{Study size}

The study size was determined by following all the people we had treated by the time the Conformité Européenne (CE) Mark for EndoBarrier was suspended in November 2017. ${ }^{12}$ This was 62, and we provide data here on all of these up until November 2019 - that is, one year after the last device removal which was in November 2018. 


\section{Statistical methods}

Baseline data were compared with follow-up data using the paired Student t-test for parametric data and the Wilcoxon signed-rank test for non-parametric data. When comparing data which was not paired (attended vs DNA), we used the unpaired Student t-test for parametric data and the Mann-Whitney $U$ test for non-parametric data. Changes in insulin dose were assessed using the $\mathrm{X}^{2}$ test.

\section{Results}

Between October 2014 when the service commenced and November 2017 when the last EndoBarrier was inserted, 62 people with diabetes received treatment with EndoBarrier and we have previously reported the outcomes during the year with EndoBarrier in all of these people. ${ }^{8}$ One year after removal of the EndoBarrier, 46/62 (72\%) people with diabetes attended followup and 16/62 (28\%) did not attend. The reasons for their nonattendance are shown in Table 1 . As word of our service spread, we had some referrals from far away. As a result, one of the important reasons for non-attendance was the distance required to travel to clinic for appointments. As previously detailed, ${ }^{8}$ one of the patients had had their EndoBarrier removed after just 18 days for a gastrointestinal haemorrhage caused by non-compliance with mandatory dietary advice for the two weeks following EndoBarrier insertion. There were no follow-up data for this patient. We therefore had follow-up data after EndoBarrier insertion in 61/62 (98.4\%) people with diabetes, 46 of whom attended and 15 of whom did not attend follow-up one year after EndoBarrier removal. Table 2 shows the baseline characteristics of the 46 people with diabetes who attended follow-up 12 months after removal (mean \pm SD age $51.5 \pm 7.7$ years, $52 \%$ male, $54.3 \%$ white ethnicity, median (IQR) diabetes duration 14.5 (8-20) years, $67.4 \%$ insulin treated and mean \pm SD BMI $\left.41.6 \pm 7.1 \mathrm{~kg} / \mathrm{m}^{2}\right)$. The 15 people with diabetes who did not attend follow-up had a lower duration of diabetes, although this did not achieve statistical significance. The only significant difference was that the nonattenders were less likely to be taking insulin at baseline.

Table 3 compares the impact of EndoBarrier on weight and $\mathrm{HbA}_{1 \mathrm{c}}$ between the attenders and non-attenders. It can be seen that the non-attenders had significantly less weight loss in response to EndoBarrier than those who attended one year after removal $(12.0 \pm 6.3 \mathrm{~kg}$ vs $17.2 \pm 8.8 \mathrm{~kg}, \mathrm{p}=0.037)$.

Table 4 shows the main outcomes during the period of EndoBarrier implantation for the 46 people with diabetes who attended follow-up. Mean \pm SD HbA 1 c fell by $21.1 \pm 19.6 \mathrm{mmol} / \mathrm{mol}$ from $77.1 \pm 20.0$ to $56.0 \pm 11.2 \mathrm{mmol} / \mathrm{mol}(\mathrm{p}<0.001$ ) (by $1.9 \pm 1.8 \%$ from $9.2 \pm 1.8 \%$ to $7.3 \pm 1.0 \%(p<0.001))$, weight fell by $17.2 \pm 8.8$ $\mathrm{kg}$ from $121.9 \pm 29.4 \mathrm{~kg}$ to $104.7 \pm 30.1 \mathrm{~kg}(p<0.001)$, BMl fell from $41.6 \pm 7.5$ to $35.5 \pm 7.5 \mathrm{~kg} / \mathrm{m}^{2}(p<0.001)$, systolic blood pressure from $139.0 \pm 14.0$ to $126.0 \pm 14.6 \mathrm{mmHg}(p<0.001)$ and serum alanine aminotransferase from $30.0 \pm 16.9$ to $18.8 \pm 11.0$ $\mathrm{U} / \mathrm{L}(\mathrm{p}<0.001)$. Median (IQR) total daily insulin dose reduced from $104(54-162)$ to $30(0-62)$ units $(n=31, p<0.001) ; 10 / 31$ (32\%) insulin-treated people with diabetes were able to discontinue insulin.
Table 1 Reasons for non-attendance in the 16/62 (28\%) people with diabetes who did not attend follow-up

\begin{tabular}{ll}
\hline Reason for non-attendance at follow-up & $\mathbf{n ~ ( \% )}$ \\
No reason given & $9(56.3)$ \\
Too far to travel & $4(25.0)$ \\
Does not wish to take time off work to attend & $1(6.3)$ \\
Severe depression & $1(6.3)$ \\
Patient died 9 months after removal of EndoBarrier* & $1(6.3)$ \\
*Cause not EndoBarrier related. In memoriam, it is noteworthy that during the \\
year of EndoBarrier treatment her weight fell from 152.4 to $139.6 \mathrm{~kg}$ and that in \\
the 6 months after removal she lost more weight to $124.0 \mathrm{~kg}$. HbA 1 c fell from \\
122 to 50 mmol/mol during treatment and was 48 mmol/mol 6 months later. \\
Her insulin requirement was 100 units daily prior to EndoBarrier but she required \\
no insulin 6 months after EndoBarrier.
\end{tabular}

Table 2 Baseline characteristics of 46 people with diabetes who attended follow-up one year after EndoBarrier removal and 15 who did not attend follow-up

\begin{tabular}{llll}
\hline Parameter & $\begin{array}{l}\text { Attended } \\
(\mathbf{n = 4 6 )}\end{array}$ & $\begin{array}{l}\text { DNA } \\
(\mathbf{n}=\mathbf{1 5})\end{array}$ & P value \\
\hline Age (years) & $51.5 \pm 7.7$ & $51.1 \pm 5.6$ & 0.822 \\
Sex (\% male) & 52 & 60 & 0.597 \\
$\begin{array}{l}\text { Ethnicity: \% White } \\
\text { \% Asian-Indian }\end{array}$ & 54.3 & 66.7 & \\
\% Afro-Caribbean & 17.4 & 20 & 0.702 \\
Weight (kg) & $121.9 \pm 29.4$ & $124.8 \pm 23.6$ & 0.704 \\
BMI (kg/m²) & $41.6 \pm 7.1$ & $42.8 \pm 8.5$ & 0.613 \\
HbA1c (mmol/mol) & $77.1 \pm 20.0$ & $89.7 \pm 27.6$ & 0.119 \\
HbA1c (\%) & $9.2 \pm 1.8$ & $10.4 \pm 2.5$ & 0.119 \\
$\begin{array}{l}\text { Diabetes duration } \\
\text { (median (IQR)) (years) }\end{array}$ & $14.5(8-20)$ & $9.0(6.0-12.0)$ & 0.061 \\
Taking insulin (\%) & 67.4 & 44.4 & 0.006
\end{tabular}

With regard to what happened to the people with diabetes during the year after removal of the EndoBarrier, Table 4 shows that all parameters of the group as a whole deteriorated although all except systolic blood pressure remained significantly lower than prior to EndoBarrier treatment. In particular, weight at $110.7 \pm 28.8$ $\mathrm{kg}$ was $11.2 \pm 9.9 \mathrm{~kg}$ less than the baseline value of $121.9 \pm 29.4 \mathrm{~kg}$ $(p<0.001)$ and $\mathrm{HbA}_{1 \mathrm{c}}$ at $67.8 \pm 19.6 \mathrm{mmol} / \mathrm{mol}(8.4 \pm 2.6 \%)$ was significantly less than the baseline value of $77.1 \pm 20.0 \mathrm{mmol} / \mathrm{mol}$ $(9.2 \pm 1.8 \%)(p<0.001)$. Median (IQR) total daily insulin dose at 38 (0-80) units was considerably lower than baseline (104 (54-162) units) $(p<0.001)$ and two further insulin-treated people with diabetes were able to discontinue insulin such that 12/31 (38.7\%) insulin-treated subjects no longer required insulin.

The results shown in Table 4 for the group as a whole fail to expose the reality that many people with diabetes fully maintained the improvement achieved with EndoBarrier whilst others deteriorated back to their baseline state prior to EndoBarrier. To expose this reality we defined full maintenance of the improvement as no significant difference between the weight and $\mathrm{HbA}_{1 \mathrm{c}}$ at EndoBarrier removal and one year later. We defined partially maintained improvement as significant deterioration in both weight 
Table 3 Impact of EndoBarrier treatment on mean \pm SD weight and $\mathrm{HbA}_{1 c}$ in 46 people with diabetes who attended follow-up one year after EndoBarrier removal and 15 who did not attend follow-up

\begin{tabular}{|c|c|c|c|c|c|c|}
\hline & Parameter & Baseline & Explant & Difference & P value 1 & $P$ value 2 \\
\hline Attended & \multirow[b]{2}{*}{ Weight (kg) } & $121.9 \pm 29.4$ & $104.7 \pm 30.1$ & $-17.2 \pm 8.8$ & $<0.001$ & \multirow{2}{*}{0.037} \\
\hline DNA & & $124.8 \pm 23.5$ & $112.8 \pm 24.6$ & $-12.0 \pm 6.3$ & $<0.001$ & \\
\hline Attended & \multirow{2}{*}{$\mathrm{HbA}_{1 \mathrm{c}}(\mathrm{mmol} / \mathrm{mol})$} & $77.1 \pm 20.0$ & $56.0 \pm 11.2$ & $-21.1 \pm 19.6$ & $<0.001$ & \multirow{2}{*}{0.095} \\
\hline DNA & & $89.7 \pm 27.6$ & $57.9 \pm 12.5$ & $-31.7 \pm 25.4$ & $<0.001$ & \\
\hline Attended & \multirow{2}{*}{$\mathrm{HbA}_{1 \mathrm{c}}(\%)$} & $9.2 \pm 1.8$ & $7.3 \pm 1.0$ & $-1.9 \pm 1.8$ & $<0.001$ & \multirow{2}{*}{0.092} \\
\hline DNA & & $10.4 \pm 2.5$ & $7.5 \pm 1.1$ & $-2.9 \pm 2.3$ & $<0.001$ & \\
\hline
\end{tabular}

Table 4 Impact of EndoBarrier treatment on mean \pm SD weight, BMI, $\mathrm{HbA}_{1 c}$, systolic blood pressure, alanine aminotransferase (ALT) and insulin daily dose in the 46 people with diabetes who attended follow-up one year after EndoBarrier removal showing values at baseline, at EndoBarrier explant and at one year after explant

\begin{tabular}{|c|c|c|c|c|c|c|c|}
\hline Parameter & Baseline & Explant & Difference 1 & $P$ value 1 & 1 year after & Difference 2 & P value 2 \\
\hline Weight (kg) & $121.9 \pm 29.4$ & $104.7 \pm 30.1$ & $-17.2 \pm 8.8$ & $<0.001$ & $110.7 \pm 28.8$ & $-11.2 \pm 9.9$ & $<0.001$ \\
\hline BMI $\left(\mathrm{kg} / \mathrm{m}^{2}\right)$ & $41.6 \pm 7.5$ & $35.5 \pm 7.5$ & $-6.1 \pm 3.3$ & $<0.001$ & $37.7 \pm 7.2$ & $-3.9 \pm 3.4$ & $<0.001$ \\
\hline $\mathrm{HbA}_{1 \mathrm{c}}(\%)$ & $9.2 \pm 1.8$ & $7.3 \pm 1.0$ & $-1.9 \pm 1.8$ & $<0.001$ & $8.4 \pm 2.6$ & $-0.8 \pm 2.6$ & 0.034 \\
\hline Systolic BP (mmHg) & $139.0 \pm 14.0$ & $126.0 \pm 14.6$ & $-12.9 \pm 16.0$ & $<0.001$ & $136.9 \pm 17.0$ & $-2.1 \pm 19.1$ & 0.463 \\
\hline $\begin{array}{l}\text { Insulin daily dose } \\
\text { (median }(\text { IQR }))(n=31)^{*}\end{array}$ & $104(54-162)$ & $30(0-62)$ & -74 & $<0.001$ & $38(0-80)$ & -66 & $<0.001$ \\
\hline
\end{tabular}

and $\mathrm{HbA}_{1 \mathrm{c}}$ from between EndoBarrier removal and one year after removal but continued significant improvement in both weight and $\mathrm{HbA}_{1 \mathrm{c}}$ compared with baseline. Finally, we defined deterioration to baseline as no significant difference between baseline and one year after EndoBarrier removal. Using these definitions, as illustrated in Figure 2, 18/46 (39\%) demonstrated fully sustained improvement in weight and $\mathrm{HbA}_{1 \mathrm{c}}, 18 / 46$ (39\%) partially sustained improvement, with 10/46 (22\%) reverting to baseline. Figures $3 \mathrm{a}-\mathrm{c}$ show the weight and $\mathrm{HbA}_{1}$ c for those who fully sustained the improvement, partially sustained the improvement and deteriorated to baseline, respectively. It was noteworthy that those who deteriorated to baseline reported to us many problems in their lives and 9/10 (90\%) had depression or bereavement. Table 5, however, shows that the people with diabetes who went on to deteriorate back to baseline had had less fall in weight and $\mathrm{HbA}_{1 \mathrm{c}}$ during the period of EndoBarrier treatment than those who maintained or partially maintained the improvement.

As changes in medication during the year following EndoBarrier removal could confound the results, Table 6 shows the medications at the time of EndoBarrier removal and one year after removal in the three groups. It can be seen that there were no changes of note. Table 7 shows the number of people with diabetes taking insulin and the average number of daily units of insulin per patient in each group at baseline, at the time of
Figure 2. Figure 2 One year after removal of EndoBarrier, $18 / 46$ (39\%) fully sustained the improvement achieved during EndoBarrier treatment, 18/46 (39\%) partially sustained this improvement and 10/46 (22\%) who deteriorated back to their baseline as they were prior to EndoBarrier

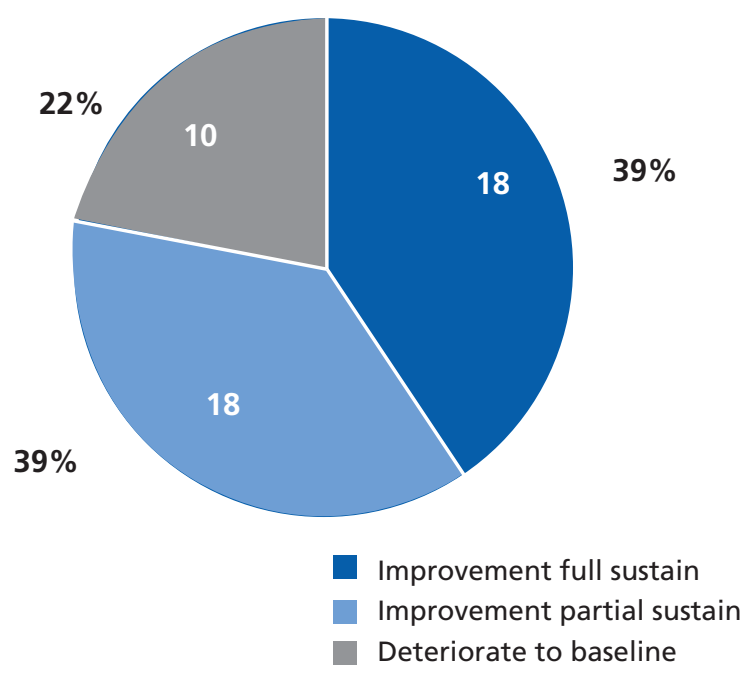


Figure 3. Weight and $\mathrm{HbA}_{1 \mathrm{c}}$ at baseline, at explant and one year after explant in (a) the 18/46 (39\%) who fully maintained the improvement achieved during EndoBarrier treatment, (b) the 18/46 (39\%) who partially maintained this improvement and also (c) the 10/46 (22\%) who deteriorated back to their baseline as they were prior to EndoBarrier.

Weight (kg)

$\mathrm{HbA}_{1 \mathrm{c}}(\%)$

(a)

\section{Improvement full sustain, $n=18$}
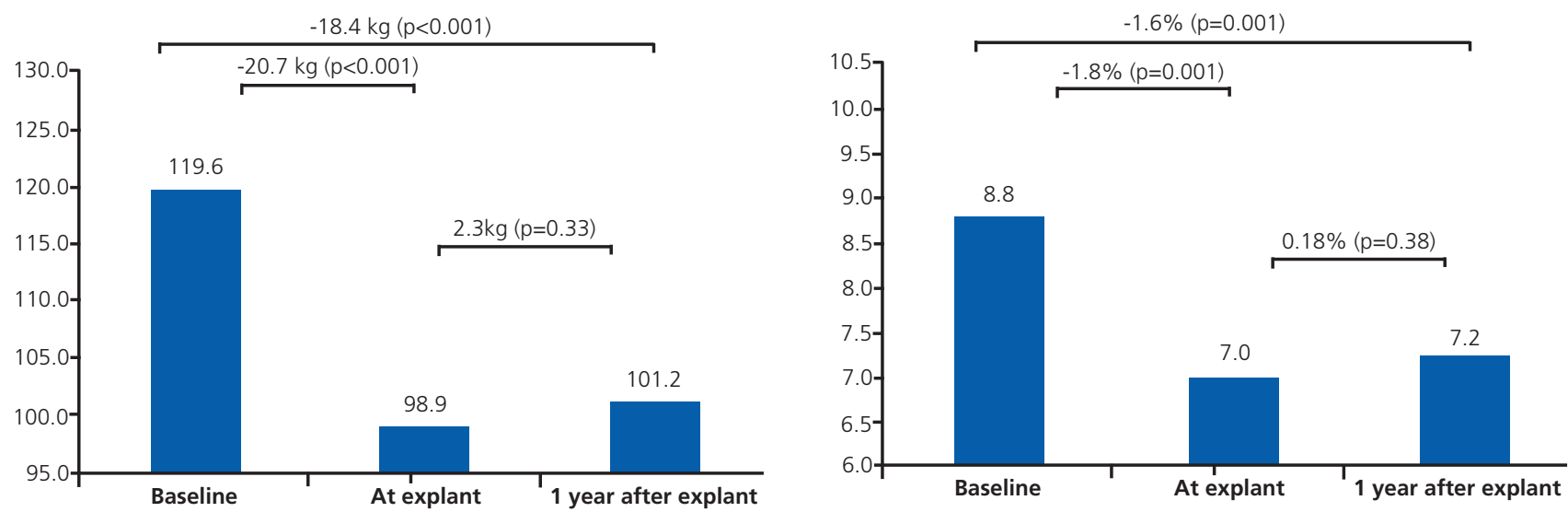

(b)

\section{Improvement partial sustain, $\mathrm{n=18}$}
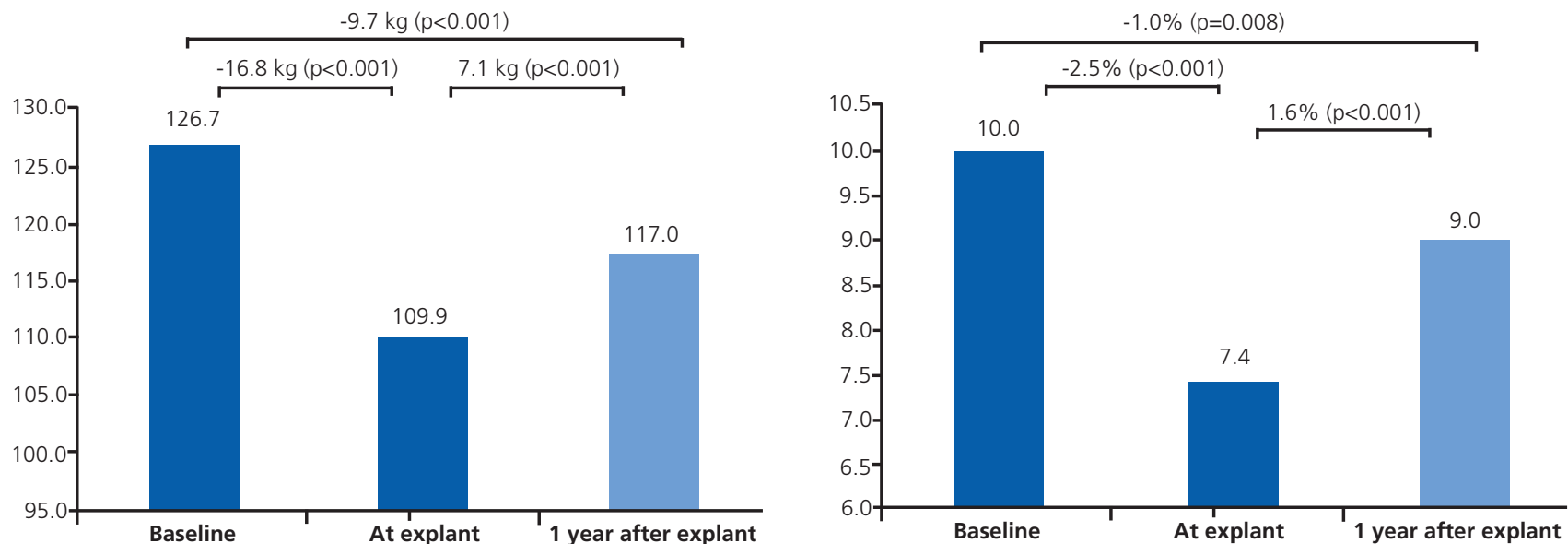

(c)
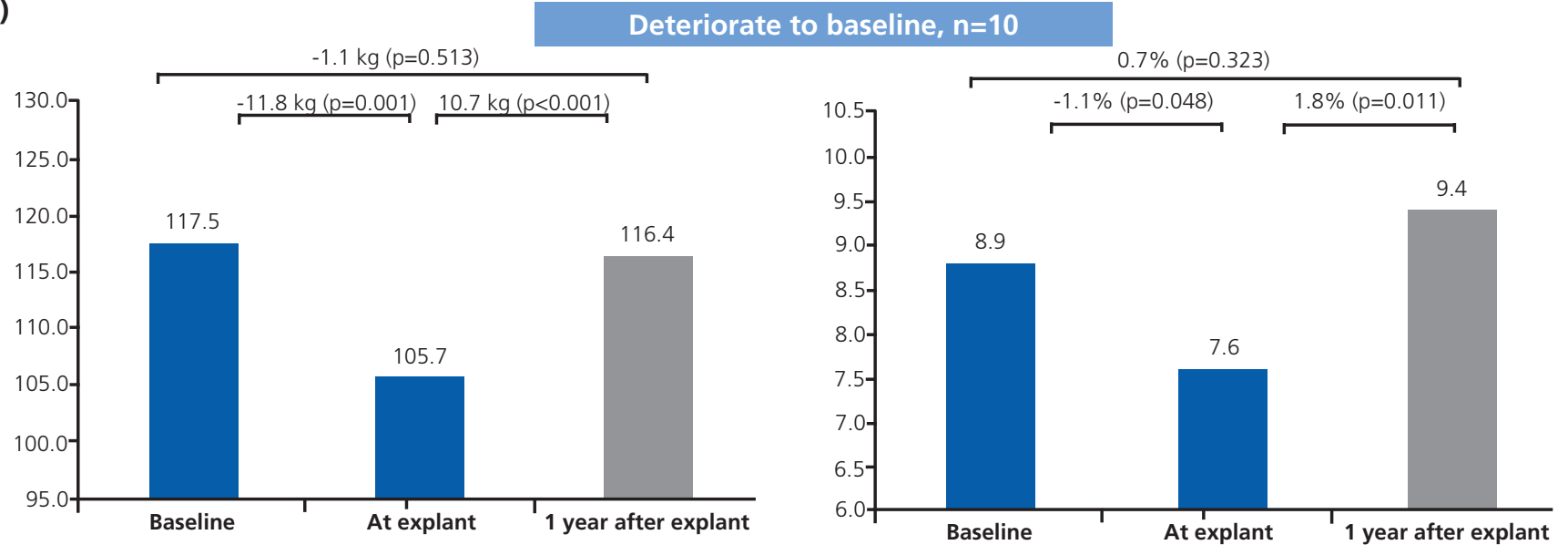
Table 5 People with diabetes who went on to deteriorate back to baseline had had less fall in mean weight and $\mathrm{HbA}_{1 \mathrm{c}}$ during the period of EndoBarrier treatment than those who maintained or partially maintained the improvement

\begin{tabular}{lll}
\hline & $\begin{array}{l}\text { Weight loss } \\
\text { during } \\
\text { EndoBarrier } \\
\text { treatment }\end{array}$ & $\begin{array}{l}\text { Fall in } \mathrm{HbA}_{1 c} \\
\text { during } \\
\text { EndoBarrier } \\
\text { treatment }\end{array}$ \\
Fully sustained $(\mathrm{n}=18)$ & $20.7 \mathrm{~kg}$ & $1.8 \%$ \\
Partially sustained $(n=18)$ & $16.8 \mathrm{~kg}$ & $2.5 \%$ \\
Deteriorated to baseline $(\mathrm{n}=10)$ & $11.8 \mathrm{~kg}$ & $1.1 \%$
\end{tabular}

EndoBarrier removal and one year after EndoBarrier removal. It can be seen that the amount of insulin required by people with diabetes in all three groups reduced during the year of EndoBarrier treatment but that, in the group who sustained the improvement, the insulin requirement continued to fall after EndoBarrier removal whereas in the partially sustained group it rose although remaining at only $53.5 \%$ of baseline. In the group who deteriorated the insulin requirement rose most to $85.7 \%$ of baseline.

\section{Discussion}

People with long-standing type 2 diabetes, with poor glycaemic control and obesity, especially those treated with insulin, find it difficult to lose weight and improve their glycaemic control. Many continue to have a high $\mathrm{HbA}_{1 \mathrm{c}}$ and to remain obese despite GLP1 receptor agonists and SGLT2 inhibitors. We need new treatments to help such people.

\section{Key results}

We have shown here that in the year following EndoBarrier treatment, amongst the $72 \%$ who attended follow-up a year later, $39 \%$ were able to sustain the full improvement achieved during the year with EndoBarrier (ie, they showed no significant difference between weight and $\mathrm{HbA}_{1 \mathrm{c}}$ at EndoBarrier removal and one year later), 39\% partially sustained the improvement (ie, they showed a significant deterioration in both weight and $\mathrm{HbA}_{1 \mathrm{c}}$ between EndoBarrier removal and one year after removal but remained significantly improved in both weight and $\mathrm{HbA}_{1 \mathrm{c}} \mathrm{com}-$ pared with baseline) and $22 \%$ deteriorated to baseline (ie, they showed no significant difference between baseline and one year after EndoBarrier removal). It was noteworthy that those who reverted to baseline experienced less improvement in weight and $\mathrm{HbA}_{1 \mathrm{c}}$ during the year with EndoBarrier and most had experienced depression or bereavement during the year following EndoBarrier. These findings enhance our previous report of considerable improvement in weight, glycaemic control, a marker of liver fat and cardiovascular risk, as well as reduction in the need

Table 6 Medications at the time of EndoBarrier removal and one year after EndoBarrier removal in the 18/46 (39\%) people with diabetes who fully sustained the improvement, 18/46 (39\%) who partially sustained the improvement and the 10/46 (22\%) who deteriorated back to baseline

\begin{tabular}{|c|c|c|c|c|c|c|}
\hline \multirow[t]{2}{*}{ Medication } & \multicolumn{2}{|c|}{ Sustained improvement } & \multicolumn{2}{|c|}{ Partially sustained improvement } & \multicolumn{2}{|c|}{ Deteriorated to baseline } \\
\hline & At explant & 1 year later & At explant & 1 year later & At explant & 1 year later \\
\hline Metformin & $15 / 18(83.3 \%)$ & $14 / 18(77.8 \%)$ & $17 / 18(94.4 \%)$ & $16 / 18(88.9 \%)$ & $9 / 10(90 \%)$ & 9/10 (90\%) \\
\hline SGLT2 inhibitor & $6 / 18(33.3 \%)$ & $8 / 18(44.4 \%)$ & $8 / 18(44.4 \%)$ & $8 / 18(44.4 \%)$ & $3 / 10(30 \%)$ & $4 / 10(40 \%)$ \\
\hline Pioglitazone & $3 / 18(16.7 \%)$ & $6 / 18(33.3 \%)$ & $5 / 18(27.8 \%)$ & $6 / 18(33.3 \%)$ & $3 / 10(30 \%)$ & $3 / 10(30 \%)$ \\
\hline Metiglinide & $1 / 18(5.6 \%)$ & $0 / 18(0 \%)$ & $1 / 18(5.6 \%)$ & $1 / 18(5.6 \%)$ & $1 / 10(10 \%)$ & $1 / 10(10 \%)$ \\
\hline Insulin & $5 / 18(27.8 \%)$ & $4 / 18(22.2 \%)$ & $9 / 18(50 \%)$ & $10 / 18(55.6 \%)$ & $5 / 10(50 \%)$ & $5 / 10(50 \%)$ \\
\hline
\end{tabular}

Table 7 Number of people with diabetes taking insulin and average number of daily units of insulin per person in the group at baseline, at the time of EndoBarrier removal and one year after EndoBarrier removal in the 18/46 (39\%) who fully sustained the improvement, $18 / 46$ (39\%) who partially sustained the improvement and also the 10/46 (22\%) who deteriorated back to baseline

\begin{tabular}{|c|c|c|c|c|c|c|}
\hline \multirow{2}{*}{$\begin{array}{l}\text { Outcome } 1 \text { year } \\
\text { after EndoBarrier } \\
\text { removal }\end{array}$} & \multicolumn{2}{|l|}{ Baseline } & \multicolumn{2}{|l|}{ At explant } & \multicolumn{2}{|l|}{1 year later } \\
\hline & $\begin{array}{l}\text { Number (\%) } \\
\text { taking } \\
\text { insulin }\end{array}$ & $\begin{array}{l}\text { Average } \\
\text { units } \\
\text { of insulin }\end{array}$ & $\begin{array}{l}\text { Number }(\%) \\
\text { taking } \\
\text { insulin }\end{array}$ & $\begin{array}{l}\text { Average } \\
\text { units } \\
\text { of insulin }\end{array}$ & $\begin{array}{l}\text { Number (\%) } \\
\text { taking } \\
\text { insulin }\end{array}$ & $\begin{array}{l}\text { Average } \\
\text { units } \\
\text { of insulin }\end{array}$ \\
\hline Sustained improvement & $13 / 18(72.2 \%)$ & 77 & $5 / 18(27.8 \%)$ & 23 & $5 / 18(27.8 \%)$ & 9 \\
\hline Partially sustained improvement & $11 / 18(61.1 \%)$ & 112 & $9 / 18(50 \%)$ & 38 & $10 / 18(55.6 \%)$ & 60 \\
\hline Deteriorated to baseline & $6 / 10(60 \%)$ & 50 & $5 / 10(50 \%)$ & 33 & $5 / 10(50 \%)$ & 43 \\
\hline
\end{tabular}


for insulin that we found for EndoBarrier treatment in the first NHS service. ${ }^{8}$

\section{Strengths}

People with diabetes on insulin and with elevated BMI are a difficult to treat group. People in this observational cohort study had a median diabetes duration of 14.5 years and $67.4 \%$ were insulin treated. We need to add to our existing armamentarium of interventions. In the current climate it would be difficult to offer bariatric surgery to most of this cohort of people both in terms of logistics and funding. Our study demonstrated considerable clinical benefit to such a group of people and also demonstrated that, with sufficient clinical support during follow-up, this benefit can be maintained in most.

\section{Limitations}

As reported in our original paper, ${ }^{8}$ the main limitation of this audit of a service is the lack of a control group. All the people involved had a long history of attempts at weight loss and using diabetes medications known to help with weight loss, such as GLP-1 receptor agonists and SGLT2 inhibitors, but nevertheless we cannot be sure in this cohort study what contribution there might have been from a placebo effect or the more intense follow-up. Also, we have only limited information about the $28 \%$ of people who did not attend follow-up. We know that many felt it was too far to travel to clinic (Table 1). They were also less likely to be taking insulin at baseline (Table 2) and they lost less weight during the treatment with EndoBarrier (Table 3), but we do not know the extent to which they maintained or did not maintain the improvements.

\section{Serious adverse events}

In our previous publication ${ }^{8}$ we gave details of the 10 out of 62 people with diabetes requiring early removal due to side effects (four gastrointestinal haemorrhage, two liver abscess, one other abscess, and three gastrointestinal symptoms), all of whom made a full recovery following device removal with most deriving considerable benefit despite the early removal. ${ }^{8}$ We also stated that a number of these adverse events could have been avoided by patient compliance with mandatory advice and pointed out that, in future services, such problems could be reduced by stronger re-enforcement of such advice. In particular: (1) to strictly follow a liquid diet in the first week after implantation of EndoBarrier and a pureed diet during the second week; (2) to ensure that all food is thoroughly chewed before swallowing, in particular food such as steak; and (3) to comply with mandated anti-acid medications (proton pump inhibitors or $\mathrm{H}_{2}$-receptor antagonists).

In the current pivotal trial with EndoBarrier in the USA, ${ }^{13}$ daily temperature monitoring is being mandated with remote monitoring such that the liver abscess complication can be detected and treated early. Such a precaution could further reduce complications and should be considered in the set-up of future services.

\section{Interpretation}

We have previously pointed out that the improvements associated with EndoBarrier treatment are likely to impact both microvascular

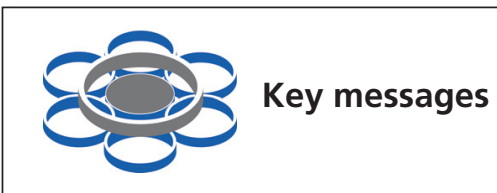

- In people with obesity, poor glycaemic control and long duration of diabetes, we have previously demonstrated that EndoBarrier led to a considerable improvement in weight and microvascular risk, as indicated by improvement in blood pressure and glycaemic control. We also demonstrated a significant reduction in cardiovascular risk as assessed by the UKPDS risk engine.

- We have now demonstrated that a year following removal of EndoBarrier, 39\% of people with diabetes maintained the full improvement achieved during EndoBarrier treatment, $39 \%$ partially maintained this improvement, with $22 \%$ deteriorating to their baseline as they were prior to EndoBarrier. Those deteriorating tended to have depression or bereavement.

- We previously demonstrated that all people with diabetes requiring early removal for serious adverse events or side effects (16\%) fully recovered, and despite early removal, most derived benefit. In many, such problems could have been avoided by improved education and vigilance.

- Patient satisfaction levels were high and these results from the first NHS EndoBarrier service are encouraging for EndoBarrier as a treatment for people with long duration diabetes and obesity with poor glycaemic control despite other diabetes treatments.

and macrovascular complications and the general long-term health outlook for the people so treated. ${ }^{8}$ We have shown here that, in the year following EndoBarrier removal, $78 \%$ of people with diabetes for whom data were available were able to maintain significant improvement, which is encouraging for EndoBarrier as a potential relatively simple treatment sitting between diet and lifestyle measures with pharmacological therapies on the one hand and bariatric surgery on the other.

A meta-analysis of EndoBarrier treatment in people with type 2 diabetes and obesity ${ }^{2}$ identified two studies with follow-up data 12 months after EndoBarrier removal ${ }^{14,15}$ and concluded that, whilst the weight remained significantly lower than baseline (10.7 $\mathrm{kg}$ ), the $\mathrm{HbA}_{1 c}$ was not significantly different compared with baseline. ${ }^{2}$ In one of these studies ${ }^{14}$ the $\mathrm{BMI}, \mathrm{HbA}_{1 \mathrm{c}}$ and duration of diabetes was notably less than in our study. In the other study, ${ }^{15}$ whilst the baseline $\mathrm{HbA}_{1 c}$ and duration of diabetes were similar to our study, the baseline BMI was again considerably less. Neither study considered the possibility that within the overall result there might have been groups who maintained the improvement and deteriorated to baseline, as we have done. However, one of the studies ${ }^{15}$ compared people with diabetes with $\mathrm{HbA}_{1 \mathrm{c}} \leqslant 7 \%$ at EndoBarrier explant with those with $\mathrm{HbA}_{1 \mathrm{c}}>7 \%$ and demon- 
strated that the former maintained the improvement one year after EndoBarrier, suggesting that their people with diabetes, like ours, divided into groups who responded differently. The apparently greater success in our study may also be related to the level of support we gave to our people with diabetes during the year after EndoBarrier, as described in the Methods section.

EndoBarrier treatment requires only a relatively quick and easy endoscopy procedure and it is noteworthy that endoscopy units and skilled endoscopists are ubiquitous throughout the NHS. In the context of the diabesity pandemic, ${ }^{16}$ there is a need for simpler treatments that are less invasive than bariatric surgery for the many people with obesity and poorly controlled diabetes despite diet and lifestyle and pharmaceutical interventions. As demonstrated by their responses to the NHS Friends and Family Test, 8,11 EndoBarrier was popular among those who received the treatment, and the benefits to those concerned are most readily appreciated from the pictorial examples ${ }^{17}$ and from interviews with them, ${ }^{18}$ both of which can be readily viewed online. ${ }^{17,18}$ EndoBarrier therefore deserves further investigation as a potential treatment for wider use in people with long-standing poorly controlled type 2 diabetes and obesity, especially bearing in mind the cardiovascular and microvascular risks to these people if they are not given additional treatment.

\section{Generalisability}

Future use of EndoBarrier within the NHS is dependent on restoration of the CE mark, which was not renewed in November 2017 by the notified body at the time for reasons that are not entirely clear. $^{12}$ In 2021 the makers of EndoBarrier are re-applying for restoration of the CE mark and are hopeful that it will be achieved..$^{19}$ In the light of our experience with EndoBarrier and the obvious benefits to the people we have treated, we also hope for the restoration of permission to use this form of treatment in the UK. With the increased safety measures that we would recommend, as detailed above, we believe the risk benefit ratio is strongly towards benefit. Endoscopy units are ubiquitous throughout the NHS, as are skilled endoscopists. There is a worldwide pandemic of type 2 diabetes and obesity, ${ }^{16}$ and thus there are also very many people with long-standing poorly controlled type 2 diabetes and obesity throughout the NHS. Therefore, should permission for use in the UK be restored, it would be relatively easy to make EndoBarrier treatment widely available.

Acknowledgement The success of the project was down to a team effort with many people involved. We would like thank in particular all of the endoscopy, anaesthetic and diabetes staff involved in the care of these patients, and Dominic Jackson from Elemental Healthcare Limited who supported with his long-standing expertise with EndoBarrier. Special thanks to Melanie Wyres who was the administrative rock at the core of the project. Finally, thanks to our chief executive, Toby Lewis, for his crucial support in getting this innovative new service established in our busy hospital despite so many other priorities, and for facilitating negotiations with the local CCG.

Conflict of interest $\mathrm{Dr}$ Bob Ryder has received speaker fees, and/or consultancy fees and/or educational sponsorships from AstraZeneca, BioQuest, GI Dynamics, Janssen and Novo Nordisk. All other co-authors have nothing to declare. Funding None.

\section{References}

1. Instructions for Use - EndoBarrier GI Liner with Delivery System - GID part number 50-10-00552 Rev N. http://gidynamics.com/wp-content/uploads/ 2017/09/50-10-00552-Rev-N-IFU-EB-GI-Liner-with-Delivery-System.pdf (accessed 12 March 2021).

2. Jirapinyo, Haas AV, Thompson CC. Effect of the duodenal-jejunal bypass liner on glycemic control in patients with type 2 diabetes with obesity: a metaanalysis with secondary analysis on weight loss and hormonal changes. Diabetes Care 2018;41(5):1106-15. https://doi.org/10.2337/dc17-1985

3. Laubner K, Riedel N, Fink K, et al. Comparative efficacy and safety of the duodenal-jejunal bypass liner in obese patients with type 2 diabetes mellitus: a case control study. Diabetes Obes Metab 2018;20(8):1868-77. https://doi.org/10.1111/dom.13300

4. de Jonge C, Rensen SS, Verdam FJ, et al. Endoscopic duodenal-jejunal bypass liner rapidly improves type 2 diabetes. Obes Surg 2013;23:1354-60. https://doi.org/10.1007/s11695-013-0921-3

5. Betzel B, Homan J, Aarts EO, et al. Weight reduction and improvement in diabetes by the duodenal-jejunal bypass liner: a 198 patient cohort study, Surg Endosc 2017;31:2881-91. https://doi.org/10.1007/s00464-016-52996

6. Kaválková P, Mráz M, Trachta P, et al. Endocrine effects of duodenal-jejunal exclusion in obese patients with type 2 diabetes mellitus. J Endocrinol 2016;231(1):11-22. https://doi.org/10.1530/JOE-16-0206

7. Koehestanie P, Dogan K, Berends F, et al. Duodenal-jejunal bypass liner implantation provokes rapid weight loss and improved glycemic control, accompanied by elevated fasting ghrelin levels. Endosc Int Open 2014; 2(1):E21-E27. https://doi.org/10.1055/s-0034-1365222

8. Ryder REJ, Irwin SP, Burbridge W, et al. The United Kingdom's first NHS Endobarrier service for advanced diabesity: 1-year outcomes for all 62 treated patients. Br J Diabetes 2019;19:110-17. https://doi.org/10.15277/ bjd. 2019.226

9. Hayee B, Sen Gupta P, Anderson M, et al. Endoscopic proximal intestinal exclusion can improve non-alcoholic fatty liver disease (NAFLD) in patients with diabesity. Proceedings of the Digestive Diseases Week (DDW), San Diego, May 2016.

10. The UKPDS Risk Engine v2.0. https://www.dtu.ox.ac.uk/riskengine/ (accessed 18 February 2021).

11. NHS England. Friends and Family Test. https://www.england.nhs.uk/fft/ (accessed 18 February 2021).

12. GI Dynamics. GI Dynamics receives CE Certificate of Conformity withdrawal notice for EndoBarrier. https://gidynamics.com/2017/11/12/gi-dynamics-receives-ce-certificate-conformity-withdrawal-notice-endobarrier/ (accessed 18 February 2021).

13. EndoBarrier System Pivotal Trial ( Rev B) (STEP-1). https://clinicaltrials.gov/ ct2/show/NCT04101669 (accessed 12 March 2021).

14. Betzel B, Koehestanie P, Homan J, et al. Changes in glycemic control and body weight after explantation of the duodenal-jejunal bypass liner. Gastrointest Endosc 2017;85(2):409-15. https://doi.org/10.1016/j.gie.2016.07.027

15. Vilarrasa N, Ruiz de Gordejuela AG, Casajoana A, et al. Endobarrier ${ }^{\circledR}$ in grade i obese patients with long-standing type 2 diabetes: role of gastrointestinal hormones in glucose metabolism. Obes Surg 2017;27(3):569-77. https://doi.org/10.1007/s11695-016-2311-0

16. International Diabetes Federation. Worldwide toll of diabetes. IDF Diabetes Atlas. 9th Edition, 2019. https://www.diabetesatlas.org/en/sections/worldwide-toll-of-diabetes.html (accessed 18 February 2021).

17. Birmingham EndoBarrier Treated Patients. Pictures obtained with written consent for online publication. http://www. diabetologists-abcd.org.uk/Endobarrier/Birmingham_Endobarrier_patients.pdf (accessed 18 February 2021).

18. Interviews with Birmingham EndoBarrier Treated Patients. Video footage obtained with written consent for online publication. https://tinyurl.com/ y4pwwokc (accessed 18 February 2021).

19. Gl Dynamics Announces Selection of New Notified Body. https://gidynamics.com/2018/10/05/gi-dynamics-announces-selection-new-notified-body/ (accessed 18 February 2021). 